\title{
Phenolic Plant Extracts Induce Sirt1 Activity and Increase Antioxidant Levels in the Rabbit's Heart and Liver
}

\author{
G. Corbi $\left(\mathbb{D},{ }^{1}\right.$ V. Conti $\left(\mathbb{D},{ }^{2}\right.$ K. Komici $\left(\mathbb{D},{ }^{1}\right.$ V. Manzo $\left(\mathbb{D},{ }^{2}\right.$ A. Filippelli $\left(\mathbb{D},{ }^{2}\right.$ M. Palazzo, ${ }^{3}$ \\ F. Vizzari $(i),{ }^{3}$ S. Davinelli $\left(1,{ }^{1}\right.$ A. Di Costanzo, ${ }^{1}$ G. Scapagnini, ${ }^{1}$ N. Ferrara $\left(\mathbb{1},{ }^{4}\right.$ \\ and D. Casamassima ${ }^{3}$ \\ ${ }^{1}$ Department of Medicine and Health Sciences, University of Molise, Campobasso, Italy \\ ${ }^{2}$ Department of Medicine and Surgery, University of Salerno, Salerno, Italy \\ ${ }^{3}$ Department of Agricultural, Environmental and Food Sciences, University of Molise, Campobasso, Italy \\ ${ }^{4}$ Department Translational Medical Sciences, University of Naples Federico II, Naples, Italy \\ Correspondence should be addressed to G. Corbi; graziamaria.corbi@unimol.it and K. Komici; klara.komici@unimol.it
}

Received 9 February 2018; Revised 4 May 2018; Accepted 6 June 2018; Published 4 July 2018

Academic Editor: Ilaria Peluso

Copyright ( $\odot 2018$ G. Corbi et al. This is an open access article distributed under the Creative Commons Attribution License, which permits unrestricted use, distribution, and reproduction in any medium, provided the original work is properly cited.

\begin{abstract}
Background. Several dietary phytochemicals potentially regulate the equilibrium between oxidant and antioxidant species. The aim of this study was to evaluate the effects of Lippia citriodora, Raphanus sativus, and Solanum lycopersicum on blood parameters, oxidative/antioxidant status, and SIRT1 activity in the rabbit's heart and liver. Methods. Twenty rabbits were divided into 4 groups of 5 animals each. The control group $(\mathrm{CN})$ received a feed without any additives. One intervention group received a supplement containing verbascoside (VB), another Raphanus sativus extract (RAP), and lastly lycopene (LYC). Oxidantantioxidant parameters and SIRT1 activity were measured in plasma and in the heart and liver, respectively. Results. The treatment with VB, RAP, and LYC resulted in a marked improvement in the blood lipid and glycaemic profile in respect to CN. VB was the most effective, but all three plant extracts induced a significant reduction in oxidant parameters as well as an increase in antioxidant tissue activity and vitamin A and E levels. SIRT1 activity was significantly increased in both VB and LYC compared to $\mathrm{CN}$, but the increased levels in the VB group were far the highest. The multivariate analysis suggests that the benefits of VB, particularly the antiglycaemic and antioxidant effects, might be mediated by increasing SIRT1 activity.
\end{abstract}

\section{Introduction}

Aging is a phenomenon universally involving all organisms, and it is characterized by a progressive decline of physiological function, mainly the cardiovascular and metabolic profile, leading to death. In the last decades, the prevalence of the aging population is rising progressively, and this "aging boom" has led to augmented investigation in the mechanisms involved in the aging genesis and progression [1]. A global consensus identifies aging as a multifactorial process genetically determined and epigenetically influenced by the environment. However, many theories of aging have been proposed, most of them considering the reactive oxygen species (ROS) and the oxidant/antioxidant equilibrium as crucial protagonists in aging genesis and progression [2]. Several studies have suggested that the increased ROS induce cellular damage and mitochondrial dysfunction influences the aging process. Based on these results, interesting models focused on antioxidant supplementation as an antiaging strategy have been developed [3-5].

Sirtuins, nicotinamide adenine dinucleotide- (NAD-) dependent protein deacetylases, have shown to mediate many pathways in metabolism, cardiovascular disease, and longevity of mammalian organisms [6]. In a broad range of experimental models, sirtuins proved to play a very important role against oxidative damage [7]. For instance, some studies have suggested that sirtuins deacetylate the antioxidant enzyme manganese superoxide dismutase (SOD2) in 
the mitochondrial matrix, resulting in increased scavenging of ROS [8]. Other interesting studies have described that the expression of several antioxidant genes such as superoxide dismutase, catalase, peroxiredoxins 3 and 5, thioredoxin 2, and thioredoxin reductase 2 is regulated by sirtuin isoform 1 (SIRT1) through deacetylation of the transcription factor FoxO3a and the transcriptional coactivator peroxisome proliferator-activated receptor $\gamma$-coactivator $1 \alpha$ (PGC-1 $\alpha)$ pathway $[9,10]$. The emerging data on the beneficial effects of sirtuin activators on aging and age-related diseases have focused on sirtuins as a new potential target $[11,12]$. In fact, SIRT1 activators are intensively investigated for their ability to treat metabolic disorders, inflammation, and endothelial dysfunction, with a possible implication in the clinical therapy management $[13,14]$. Recently, the use of dietary plant phenolic extracts is becoming an attractive alternative therapy. In fact, the use of these compounds has been mainly recognized as part of dyslipidaemia treatment and vascular wall health [15], as well as of neuroprotection [16]. The most interesting plant extract components that could have a therapeutic application are lycopene (Solanum lycopersicum L.), horseradish (Raphanus sativus L.), and verbascoside (Lippia citriodora) [17]. It has been previously demonstrated that a dietary supplementation with lycopene, horseradish, and verbascoside has a positive effect on plasma oxidative status in an animal model of adult rabbits. In addition, Campo and colleagues $[18,19]$ have reported that the administration of verbascoside in subjects with cardiovascular risk factors reduced the platelet aggregation values. Although the modulation of the biochemical profile and oxidative status seems to be strongly associated with sirtuin activity and phenolic extracts have some beneficial effects on it, surprisingly, no data are reported on the role of phenolic components in sirtuin activity. In the present study, we aimed to evaluate the dietary effects of plant extracts, Lippia citriodora (verbascoside), horseradish (Raphanus sativus L.), and lycopene (Solanum lycopersicum L.), on blood parameters, plasma oxidant/antioxidant status, and SIRT1 activity in the rabbit's heart and liver tissues.

\section{Methods}

2.1. Animals and Experimental Design. All breeding procedures and the management of animals were conducted in compliance with the European directive 2010/63/EU, concerning the protection of animals used for scientific purposes. The Ethic and Scientific Committee of the University of Molise approved the full experimental design. The experiment was conducted on 20 weaned male rabbits (New Zealand white and Californian) and lasted 80 days. The animals were reared in cages (two per cage) equipped with feeders and automatic watering. Temperature and relative humidity of the rabbitry were recorded continuously using a digital thermograph located at the height of the cages. The rabbitry was equipped with an environmental microclimate control system in order to maintain a temperature of $18 \pm 4^{\circ} \mathrm{C}$ and a relative humidity of $70 \pm 5 \%$ throughout the experimental period.

Rabbits were randomly divided into four groups of 5 animals each, matched by age ( $38 \pm 2$ days) and body weight $(1.49 \pm 0.07 \mathrm{~kg})$. The control group $(\mathrm{CN})$ received a fattening feed without any natural supplements, conversely to the other experimental groups. One intervention group received a supplement of Lippia citriodora extract, containing verbascoside $5 \mathrm{mg} / \mathrm{kg}$ feed (VB group), another group received $350 \mathrm{mg}$ of root extract of Raphanus sativus/kg feed (RAP group), and the last one received $5 \mathrm{mg}$ of lycopene, extracted from tomato fruit/kg feed (LYC group). The feed was administered ad libitum and was produced by Agrizoo s.n.c. (Miranda, Isernia, Italy). Feed additives based on Lippia citriodora ( $0.5 \%$ of verbascoside as the main component), horseradish (Raphanus sativus dry root extract with enzyme complex Inuzyme ${ }^{\circledR}$ ), and lycopene (2\% of Solanum lycopersicum extract fruit) were provided by Sintal Zootecnica (Isola Vicentina, Vicenza, Italy), Erba Vita Italia S.p.A. (Montegrimano Terme, Perugia, Italy), and Erbamea srl (San Giustino, Perugia, Italy), respectively.

2.2. Sampling and Laboratory Analysis of Blood. Individual samples were taken from the auricularis marginalis vein with the vacutainer method (Venoject, Terumo Europe N.V., Leuven, Belgium) using tubes with lithium heparin for plasma production. Blood samplings were performed at the beginning (weaning age, $0 \mathrm{~d}$ ) and at the half $(40 \mathrm{~d})$ and at the end of the experiment $(80 \mathrm{~d})$. Blood was centrifuged for $20 \mathrm{~min}$ at $3000 \mathrm{rpm}$, and the following parameters were determined on the plasma: glucose, triglycerides, total cholesterol, low-density lipoprotein (LDL) cholesterol, high-density lipoprotein (HDL) cholesterol, serum glutamic oxaloacetic transaminase (sGOT), serum glutamic pyruvic transaminase (sGPT), bilirubin, and creatinin, using a semiautomatic clinical chemistry analyzer Arco model (Biotechnical Instruments, S.p.A., Italy). Reactive oxygen metabolites (ROMs) were spectrophotometrically determined with the colorimetric method proposed by Diacron at a wavelength of $505 \mathrm{~nm}$ using a specific commercial kit [20]. The results were expressed in Carr units ( 1 Carr corresponds to $0.024 \mathrm{mmol} / \mathrm{l}$ of $\mathrm{H}_{2} \mathrm{O}_{2}$ ).

The determination of thiobarbituric acid reactive substances (TBARS) was spectrophotometrically performed according to Esterbauer and Zollern [21] using a standard curve with 1,1,3,3-tetramethoxypropane (Sigma-Aldrich, St. Louis, USA). The results were expressed as $\mu \mathrm{mol}$ of malondialdehyde (MDA)/l of plasma. Vitamins A and E were extracted from plasma samples with chloroform, according to Zhao et al. [22]. Vitamin amount was detected by HPLC (Kontron Instruments, Italy) which consisted of an automatic autosampler (HPLC Autosampler 360) with a loop of $20 \mu \mathrm{l}$, pump system (HPLC Pump 422), and a column C18 (5 $\mu \mathrm{m}$, $250 \times 4.60 \mathrm{~mm}$ ) (Phenomenex, Torrance, CA, USA). The mobile phase consisted of a mixture of acetonitrile and methanol $(85: 15 v / v)$ with a flow value of $1 \mathrm{ml} / \mathrm{min}$. Vitamins A and $\mathrm{E}$ were identified by comparing the retention time of the samples with the retention time of the pure standards (>97\%) purchased by Sigma-Aldrich (St. Louis, USA). The quantification was performed using the Gyminix system (version 1.8.1) by comparing the peak of the area with that of the reference standard curve.

2.3. Tissue Processing and Homogenate Preparation. At the end of the study period, all the rabbits were sacrificed, and 
their hearts and liver tissue were immediately removed and rinsed free of blood. The left ventricle was separated, frozen in liquid nitrogen, and stored at $-80^{\circ} \mathrm{C}$ until processing. The tissues were homogenized in lysis buffer containing $10 \mathrm{mM}$ Tris- $\mathrm{HCl}$ (pH 7.4); 0.5\% NP-40; $250 \mathrm{mM}$ sucrose; $0.1 \mathrm{mM}$ EGTA; $10 \mathrm{mM} \mathrm{NaCl} ; 15 \mathrm{mM} \mathrm{MgCl} 2 ; 1 \mathrm{mM}$ PMSF; $1 \mu \mathrm{g} / \mathrm{ml}$ each of aprotinin, leupeptin, and pepstatin; $1 \mathrm{mM}$ Na3VO4; and $1 \mathrm{mM} \mathrm{NaF}$.

After $1 \mathrm{~h}$, the homogenate was obtained by centrifugation at $14000 \mathrm{rpm}$ for $10 \mathrm{~min}$ at $4^{\circ} \mathrm{C}$. Protein concentration was determined using the Bio-Rad assay (Milan, Italy) [23].

2.4. Total Antioxidant Activity (TAC). The TAC of heart and liver supernatants was measured using the ability of endogenous antioxidants to scavenge the 2,2' -azinobis(3ethylbenzothiazoline-6-sulfonic acid) (ABTS) radical cation decolorization assay, according to the method of Re et al. [24]. The ABTS radical was generated by chemical reaction with potassium persulphate. For this purpose, $25 \mathrm{ml}$ of ABTS $(7 \mathrm{mM})$ was spiked with $440 \mu \mathrm{l}$ of potassium persulphate $(140 \mathrm{mM})$ and allowed to stand in darkness at room temperature for $12-16 \mathrm{~h}$ (time required for the formation of the radical). Trolox was used as the standard, and the total antioxidant capacity of samples was defined as the concentration of Trolox having equivalent activity which is expressed as $\mu \mathrm{mol} / \mathrm{g}$ tissue weight. Each experiment was performed in triplicate.

\subsection{Isolation and Extraction of Nuclei for SIRT1 Deacetylase} Assay. Aliquots of heart and liver tissue homogenate (without protease inhibitors) were spun through $4 \mathrm{ml}$ of $30 \%$ sucrose, $10 \mathrm{mM}$ Tris- $\mathrm{HCl}$ (pH 7.5), $10 \mathrm{mM} \mathrm{NaCl}$, and $3 \mathrm{mM} \mathrm{MgCl} 2$ at $1300 \times \mathrm{g}$ for $10 \mathrm{~min}$ at $4^{\circ} \mathrm{C}$; the pellet was washed with cold $10 \mathrm{mM}$ Tris- $\mathrm{HCl}(\mathrm{pH} 7.5)$ and $10 \mathrm{mM} \mathrm{NaCl}$. The nuclei were suspended in $50-100 \mu \mathrm{l}$ of extraction buffer containing $50 \mathrm{mM}$ Hepes $\mathrm{KOH}$ (pH 7.5), $420 \mathrm{mM} \mathrm{NaCl}, 0.5 \mathrm{mM}$ EDTA $\mathrm{Na}_{2}, 0.1 \mathrm{mM}$ EGTA, and $10 \%$ glycerol, sonicated for $30 \mathrm{~s}$, and stood on ice for $30 \mathrm{~min}$.

After centrifugation at $13000 \mathrm{rpm}$ for $10 \mathrm{~min}$, an aliquot of the supernatant (crude nuclear extract) was used to determine protein concentration using the Bio-Rad assay [23].

2.6. SIRT1 Deacetylase Expression and Activity. SIRT1 protein expression was measured using the Human SIRT1 (sirtuin 1) ELISA Kit (Elabscience ${ }^{\circledR}$ Biotechnology Inc., United States). Briefly, serially diluted standards or samples were added to the micro ELISA plate wells, precoated with an antibody specific to human SIRT1. Then, a biotinylated detection antibody specific for human SIRT1 and avidinhorseradish peroxidase (HRP) conjugate were added to each microplate well and incubated. After several washing steps, the substrate solution was added to each well. Lastly, the enzyme-substrate reaction was terminated by the addition of stop solution producing a colored reaction that was measured spectrophotometrically at a wavelength of $450 \pm 2 \mathrm{~nm}$. The optical density (OD) values were proportional to the concentration of human SIRT1, and the concentration of human SIRT1 in the samples was calculated by comparing the OD of the samples to the standard curve.
The SIRT1 deacetylase activity was evaluated in the crude nuclear extract from heart and liver tissues of all the rabbit groups. We measured SIRT1 using a deacetylase fluorometric assay kit (Sir2 Assay Kit, CycLex, Ina, Nagano, Japan). The final reaction mixture $(100 \mu \mathrm{l})$ contained $50 \mathrm{mM}$ Tris- $\mathrm{HCl}$ (pH 8.8), $4 \mathrm{mM} \mathrm{MgCl} 2,0.5 \mathrm{mM}$ DTT, $0.25 \mathrm{~mA} / \mathrm{ml}$ lysyl endopeptidase, $1 \mu \mathrm{M}$ Trichostatin A, $200 \mu \mathrm{M}$ NAD, and $5 \mu \mathrm{l}$ of nuclear samples.

The fluorescence intensity at $440 \mathrm{~nm}$ (exc. $340 \mathrm{~nm}$ ) was measured every $30 \mathrm{~s}$ for a total of $60 \mathrm{~min}$ immediately after the addition of fluorosubstrate peptide $(20 \mu \mathrm{M}$ final concentration) and normalized by protein concentration. All determinations were performed in triplicate on 10 different samples, and the results are reported as relative fluorescence/ $\mu \mathrm{g}$ of protein (AU) [23]. Each experiment was performed in triplicate.

2.7. Statistical Analysis. Blood parameters were assessed using the delta (difference between post- and pretreatment levels). After the evaluation of the normality of frequency distribution, all variables were subjected to analysis of variance using a one-way ANOVA of the statistical package SPSS 23 version. A multivariate linear regression analysis was performed when appropriate. The differences between means were considered significant for at least $p<0.05$. The results are presented as mean \pm standard deviation.

\section{Results}

All rabbits survived to the 80-day treatments; neither side effect occurred. Table 1 shows the baseline characteristics in the blood profile divided by groups. No differences were found among groups at the start of the study in glycaemic, lipid, hepatic, and renal profiles (Table 1) and in oxidantantioxidant levels as shown by ROMs, TBARs, and vitamin $A$ and E levels (Table 2). By using the delta of all parameters, measured as differences between the posttreatment and the baseline levels, significant differences were found among groups. All plant extracts were able to improve blood lipid, glycaemic, and hepatic parameters, with different efficacies among them.

In particular, $\mathrm{VB}$ was characterized by the greatest improvement in the lipid profile. In fact, a significant reduction in triglyceride level was found in VB versus $\mathrm{CN}$ $(p<0.0001)$ and VB versus RAP $(p=0.038)$ but not with respect to LYC ( $p=0.055)$ (Table 3$)$. Similarly, the delta of total cholesterol was the lowest in VB with significant differences in respect to CN and LYC (both $p<0.0001$ ) (Table 3). Also, RAP was able to significantly reduce the delta of total cholesterol in respect to $\mathrm{CN}(p<0.0001)$ and LYC $(p=0.026)$ (Table 3$)$. All treatments also reduced LDLcholesterol values in respect to $\mathrm{CN}(p<0.0001)$. On the contrary, VB supplementation was the most robust tool to increase HDL cholesterol, with significant differences in respect to all other groups (all $p<0.0001$ ) (Table 3). Moreover, $\mathrm{VB}$ induced the highest reduction in glycaemic levels in respect to CN, RAP, and LYC (all $p<0.0001$ ). Also, LYC showed a significant reduction in glycaemic levels in respect to $\mathrm{CN}(p=0.007)$ but not to RAP $(p=0.578)$ (Table 3$)$. The 
TABLE 1: Baseline lipid, glycaemic, hepatic, and renal profiles divided by groups.

\begin{tabular}{lcccc}
\hline & CN & VB & RAP & LYC \\
\hline Body weight (gr) & $1448 \pm 110.32$ & $1532 \pm 58.05$ & $1497 \pm 51.22$ & $1486.5 \pm 64.55$ \\
Triglycerides (mmol/l) & $99.08 \pm 3.85$ & $101.88 \pm 4.77$ & $100.63 \pm 6.42$ & $100.8 \pm 5.69$ \\
Total cholesterol (mmol/l) & $64.38 \pm 4.01$ & $64.44 \pm 4.82$ & $64.37 \pm 4.35$ & $65.12 \pm 2.90$ \\
LDL cholesterol (mmol/l) & $30.98 \pm 2.26$ & $30.5 \pm 1.65$ & $30.46 \pm 2.71$ & $30.67 \pm 1.96$ \\
HDL cholesterol (mmol/l) & $25.38 \pm 2.32$ & $25.92 \pm 1.20$ & $25.6 \pm 1.46$ & $25.48 \pm 1.89$ \\
Glycaemia (mmol/l) & $158.6 \pm 6.11$ & $158.6 \pm 7.40$ & $158 \pm 6.99$ & 0.885 \\
sGOT (U/l) & $18.12 \pm 1.84$ & $18.58 \pm 0.88$ & $19.58 \pm 2.46$ & $156.7 \pm 6.04$ \\
sGPT (U/l) & $25.4 \pm 3.71$ & $25.8 \pm 2.89$ & $25.44 \pm 3.09$ & 0.978 \\
Total bilirubin (mmol/l) & $1.03 \pm 0.15$ & $1.01 \pm 0.08$ & $0.96 \pm 0.13$ & 0.961 \\
Creatinin (mmol/l) & $1016 \pm 0.16$ & $1.10 \pm 0.18$ & $1.15 \pm 0.16$ & $0.962 \pm 0.13$ \\
\hline
\end{tabular}

LDL: low-density lipoprotein; HDL: high-density lipoprotein; sGOT: serum glutamic oxaloacetic transaminase; sGPT: serum glutamic pyruvic transaminase.

TABLE 2: Baseline oxidant-antioxidant levels in blood of the rabbits divided by groups.

\begin{tabular}{lcccc}
\hline & CN & VB & RAP & LYC \\
\hline ROMs (Carr units) & $153.62 \pm 15.64$ & $155.21 \pm 12.96$ & $151.01 \pm 17.34$ & $155.06 \pm 15.93$ \\
TBARS $(\mu \mathrm{mol} / \mathrm{l})$ & $1.31 \pm 0.14$ & $1.34 \pm 0.27$ & $1.32 \pm 0.22$ & $1.32 \pm 0.22$ \\
Vitamin A $(\mu \mathrm{mol} / \mathrm{l})$ & $8.93 \pm 1.04$ & $8.25 \pm 1.05$ & $8.34 \pm 1.30$ & $8.77 \pm 1.14$ \\
Vitamin E $\mu \mathrm{mol} / \mathrm{l})$ & $0.66 \pm 0.09$ & $0.64 \pm 0.11$ & $0.65 \pm 0.12$ & 0.940 \\
\hline
\end{tabular}

ROMs: reactive oxygen metabolites; TBARS: thiobarbituric acid reactive substances.

TABLE 3: Blood parameter variations on the basis of different treatments.

\begin{tabular}{|c|c|c|c|c|c|}
\hline & $\mathrm{CN}$ & VB & RAP & LYC & $p$ \\
\hline$\Delta$ Triglycerides $(\mathrm{mmol} / \mathrm{l})$ & $0.64 \pm 144^{* \S^{\circ}}$ & $-10.74 \pm 1.47$ & $-8.01 \pm 1.89^{* *}$ & $-8.15 \pm 1.64$ & $<00001$ \\
\hline$\Delta$ Total cholesterol $(\mathrm{mmol} / \mathrm{l})$ & $1.28 \pm 0.4^{* 5^{\circ}}$ & $-6.84 \pm 0.77$ & $-5.51 \pm 0.91$ & $-4.21 \pm 1.07^{* * * \S \S}$ & $<0.0001$ \\
\hline$\Delta \mathrm{LDL}$ cholesterol $(\mathrm{mmol} / \mathrm{l})$ & $1.92 \pm 1.62^{* \S^{\circ}}$ & $-5.06 \pm 0.81$ & $-3.46 \pm 0.98$ & $-4.2 \pm 0.91$ & $<0.0001$ \\
\hline$\Delta \mathrm{HDL}$ cholesterol $(\mathrm{mmol} / \mathrm{l})$ & $0.12 \pm 0.19^{* \varsigma^{\circ \circ}}$ & $2.68 \pm 0.25$ & $1.4 \pm 0.47^{* * * *}$ & $0.91 \pm 1.80^{* * * \$ \varsigma \S}$ & $<0.0001$ \\
\hline$\Delta$ Glycaemia $(\mathrm{mmol} / \mathrm{l})$ & $-0.2 \pm 2.75^{*}$ & $-9.0 \pm 1.58$ & $-1.5 \pm 1.96^{* * * *}$ & $-3.0 \pm 1.83^{* * *}$ & $<0.0001$ \\
\hline$\Delta \mathrm{sGOT}(\mathrm{U} / \mathrm{l})$ & $0.38 \pm 0.78^{* 5^{\circ 0}}$ & $-2.52 \pm 0.98$ & $-2.15 \pm 0.56^{* * * * *}$ & $-1.66 \pm 0.97^{* * *}$ & $<0.0001$ \\
\hline$\Delta \mathrm{sGPT}(\mathrm{U} / \mathrm{l})$ & $1.58 \pm 1.13^{* \S^{\circ}}$ & $-3.66 \pm 0.88$ & $-1.9 \pm 0.89$ & $-0.89 \pm 0.80$ & $<0.0001$ \\
\hline$\Delta$ Total bilirubin $(\mathrm{mmol} / \mathrm{l})$ & $-0.0180 \pm 0.15$ & $-0.16 \pm 0.15$ & $-0.05 \pm 0.37$ & $-0.52 \pm 0.04$ & 0.075 \\
\hline$\Delta$ Creatinin $(\mathrm{mmol} / \mathrm{l})$ & $0016 \pm 0.07$ & $-0.16 \pm 0.14$ & $0.15 \pm 0.13$ & $-0.15 \pm 0.12$ & 0.082 \\
\hline
\end{tabular}

$\Delta$ : differences measured between posttreatment and baseline; LDL: low-density lipoprotein; HDL: high-density lipoprotein; sGOT: serum glutamic oxaloacetic transaminase; sGPT: serum glutamic pyruvic transaminase. ${ }^{*} \mathrm{VB}$ versus $\mathrm{CN}(p<0.0001) ;{ }^{* *} \mathrm{VB}$ versus $\mathrm{RAP}(p=0.038) ;{ }^{* * *} \mathrm{VB}$ versus LYC $(p<0.0001) ;{ }^{* * * *} \mathrm{VB}$ versus $\operatorname{RAP}(p<0.0001) ;{ }^{* * * * *} \mathrm{VB}$ versus $\mathrm{RAP}(p=0.010) .{ }^{\S} \mathrm{RAP}$ versus $\mathrm{CN}(p<0.0001) ;{ }^{\S \varsigma} \mathrm{RAP}$ versus LYC $(p=0.026) ;{ }^{\S \S} \mathrm{RAP}$ versus LYC $(p=0.011) .{ }^{\circ} \mathrm{LYC}$ versus $\mathrm{CN}(p<0.0001) ;{ }^{\circ} \mathrm{LYC}$ versus $\mathrm{CN}(p=0.001) ;{ }^{\circ 00} \mathrm{LYC}$ versus $\mathrm{CN}(p=0.007)$.

RAP group showed only a partial decrease in respect to $\mathrm{CN}$, which did not achieve any significant value (Table 3 ).

All plant extracts induced a reduction in the hepatic parameters, sGOT and sGPT, in respect to $\mathrm{CN}$. VB again induced the highest reduction of sGOT $(p<0.0001)$, while no significant differences in reducing sGPT levels among the treatment groups were found (Table 4). No significant differences were found among the treatment groups in respect to $\mathrm{CN}$ and to each other in inducing total bilirubin and creatinine level variations (Table 4). In regard to oxidant and antioxidant changes, all plant extracts were able to induce a significant reduction in oxidant levels measured as ROMs and TBARS and an increase in antioxidant vitamins
$\mathrm{A}$ and $\mathrm{E}$ in respect to $\mathrm{CN}$ (all $p<0.0001$ ). No statistically significant differences were found in ROM levels among the treatment groups, whereas VB showed the highest reduction and RAP the lowest. VB was also responsible for the most important changes in TBARS, with statistically significant differences in respect to $\operatorname{RAP}(p=0.001)$ and LYC $(p=0.046)$. No differences were found between RAP and LYC.

In antioxidants, $\mathrm{VB}$ was the most effective in increasing both vitamins $\mathrm{A}$ and $\mathrm{E}$ in respect to LYC $(p<0.0001$ and $p=0.046$, resp.), without differences with RAP. However, the RAP group showed higher values in vitamin A changes in respect to LYC $(p<0.0001)$. 
TABLE 4: Oxidant-antioxidant level changes in blood of the rabbits divided by groups.

\begin{tabular}{|c|c|c|c|c|c|}
\hline & $\mathrm{CN}$ & VB & RAP & LYC & $p$ \\
\hline$\Delta$ ROMs (Carr units) & $28.84 \pm 6.24^{* \S^{\circ}}$ & $-34.49 \pm 3.62$ & $-29.81 \pm 4.01$ & $-33.99 \pm 3.26$ & $<0.0001$ \\
\hline$\Delta$ TBARS $(\mu \mathrm{mol} / \mathrm{l})$ & $0.54 \pm 0.19^{* \S^{\circ}}$ & $-0.62 \pm 0.06$ & $-0.41 \pm 0.05^{* *}$ & $-0.48 \pm 0.05^{* * *}$ & $<0.0001$ \\
\hline$\Delta$ Vitamin $\mathrm{A}(\mu \mathrm{mol} / \mathrm{l})$ & $-0.21 \pm 0.09^{* \S^{\circ}}$ & $8.49 \pm 1.02$ & $8.19 \pm 1.31^{* * * *}$ & $5.30 \pm 1.3^{* * * * * \S \S}$ & $<0.0001$ \\
\hline$\Delta$ Vitamin $\mathrm{E}(\mu \mathrm{mol} / \mathrm{l})$ & $-0.033 \pm 0.014^{* \varsigma^{\circ}}$ & $0.64 \pm 0.08$ & $0.59 \pm 0.10$ & $0.48 \pm 0.12^{* * *}$ & $<0.0001$ \\
\hline
\end{tabular}

$\Delta$ : differences measured between posttreatment and baseline; ROMs: reactive oxygen metabolites; TBARS: thiobarbituric acid reactive substances. ${ }^{*} \mathrm{VB}$ versus $\mathrm{CN}(p<0.0001) ;{ }^{* *} \mathrm{VB}$ versus RAP $(p=0.001) ;{ }^{* * *}$ VB versus LYC $(p=0.046) ;{ }^{* * * *}$ VB versus RAP $(p<0.0001) ;{ }^{* * * * *} \mathrm{VB}$ versus LYC $(p<0.0001) .{ }^{5} \mathrm{RAP}$ versus $\mathrm{CN}(p<0.0001) ;{ }^{\S \varsigma} \mathrm{RAP}$ versus LYC $(p<0.0001) .{ }^{\circ} \mathrm{LYC}$ versus $\mathrm{CN}(p<0.0001)$.

Significant differences were also found among groups in SIRT1 activity measured in the rabbit's heart and liver, with VB showing higher levels in respect to CN, RAP, and LYC (all $p<0.0001$, Figures $1(\mathrm{a})$ and 1(b)). No significant differences were found between the RAP and CN groups in SIRT1 activity in both the heart and liver, whereas higher values characterized the RAP in respect to the CN group. Finally, in the heart, LYC showed significantly higher SIRT1 activity in respect to $\mathrm{CN}(p=0.013)$ but not to RAP (Figure 1(a)), while in the liver, no differences were found (Figure 1(b)). By SIRT1 protein expression evaluation, no differences were found between groups in both the heart (Figure 1(c)) and liver (Figure 1(d)) of the rabbits.

The total antioxidant capacity (TAC) of all plant extracts was also checked by the ABTS assay. In the heart, VB was the only extract able to significantly increase $(p<0.0001)$ TAC in respect to the $\mathrm{CN}$ group, without any differences among RAP, LYC, and CN groups (Figure 2(a)). In the liver, significant differences $(p<0.0001)$ of TAC were found among all groups in respect to $\mathrm{CN}$, with the highest levels in VB $(p<0.0001)$, followed by RAP $(p<0.0001)$ and LYC $(p=0.005)$ (Figure 2(b)).

By multivariate linear regression analysis, introducing the SIRT1 activity in heart as the dependent variable, the best predictors were represented by the VB group $(p<0.0001$, $\beta=-39.490 ; 95 \%$ CI $-55.990,-23.001)$, the delta glycaemia $(p<0.0001, \beta=-18.347 ; 95 \%$ CI $-23.276,-13.418$; Figure $3(\mathrm{a}))$, the delta ROMs $(p=0.004, \beta=-1.662$; 95\% CI $-2.677,-0.646$; Figure 3(b)), and the delta TBARs $(p=0.042, \beta=-84.096 ; 95 \%$ CI $-164.686,-3.505)$. Performing the multivariate linear regression analysis, introducing the SIRT1 activity in the liver as the dependent variable, the best predictors were represented by the VB group ( $p<0.0001, \beta=-29.749 ; 95 \%$ CI $-40.941,-18.557)$, the delta glycaemia $(p=0.001, \beta=-3.742 ; 95 \%$ CI -5.714 , -1.769 ; Figure $3(\mathrm{c}))$, and the delta ROMs $(p<0.0001$, $\beta=-2.23$; $95 \%$ CI $-3.148,-1.257$; Figure 3(d)).

\section{Discussion}

Our data demonstrated the efficacy of different plant extracts on lipid and glycaemic profiles and oxidant/antioxidant status (e.g., TBARS, ROMs, TAC, and vitamins A and E). In particular, the beneficial effects of VB seem to be mediated by SIRT1 activity in both the rabbit's heart and liver, revealing for the first time the existence of a direct correlation between the VB beneficial effects and increase in SIRT1 activity.

Multiple aspects of cellular and redox signalling in response to cellular stressors are finely regulated and conserved in both animals and plants [25-27].

In this study, we suggest that the different effects of the plant extracts could be related to their diverse chemical composition. The most important benefits were obtained by a treatment with Lippia citriodora containing verbascoside $5 \mathrm{mg} / \mathrm{kg}$ feed.

Verbascoside is a polyphenol belonging to the phenolic acid subclass used as a medicinal plant, by virtue of a wide spectrum of biological activity including cardiovascular effects $[28,29]$.

In our study, the evidence that verbascoside was able not only to reduce all parameters involved in cardiovascular risk composition, such as glycaemia, total cholesterol, and LDL cholesterol, but also to induce an increase in HDL cholesterol, a well-identified protective cardiovascular factor, confirmed these effects.

Moreover, the VB effects on vitamin A and E levels reinforce the antioxidant capability of this plant extract. Previously, Rossi et al. showed that plant extracts of Verbenaceae might improve vitamin $\mathrm{E}$ status in vivo by protecting $\alpha$-tocopherol from oxidative decay [30]. Similarly, Iglesias et al. [31] reported that the procyanidins could repair oxidized $\alpha$-tocopherol in the medium-long term in fish muscle. Palazzo et al. [32] demonstrated that the increased vitamin $\mathrm{A}$ and $\mathrm{E}$ levels can be attributed to the ability of VB to strengthen and save the endogenous antioxidant system, controlling oxidative metabolism by reducing the production of reactive radical species and increasing the antioxidant activity of enzymes [33-35]. A dual mechanism of action, proposed by Palazzo et al. [32], includes the direct action of capturing free radicals during the propagation of a chain reaction and the inhibition of prooxidant enzymes as the initiation of the oxidation phase [36]. Vitamin E, in its function as a chain-breaking antioxidant, rapidly transfers its phenolic $\mathrm{H}$-atom to a lipid peroxyl radical, converting it into a lipid hydroperoxide and a vitamin E radical [37-39].

Indeed, a relationship between SIRT1 activity and vitamin $\mathrm{E}$ levels was demonstrated in the hippocampus and cerebral cortex of rodents, in which vitamin E prevented a decrease in SIRT1 expression caused by a high-fat diet [40]. Also, Zillikens et al. [41] found an interaction between vitamin $\mathrm{E}$ and SIRT1, suggesting that this interface could be 


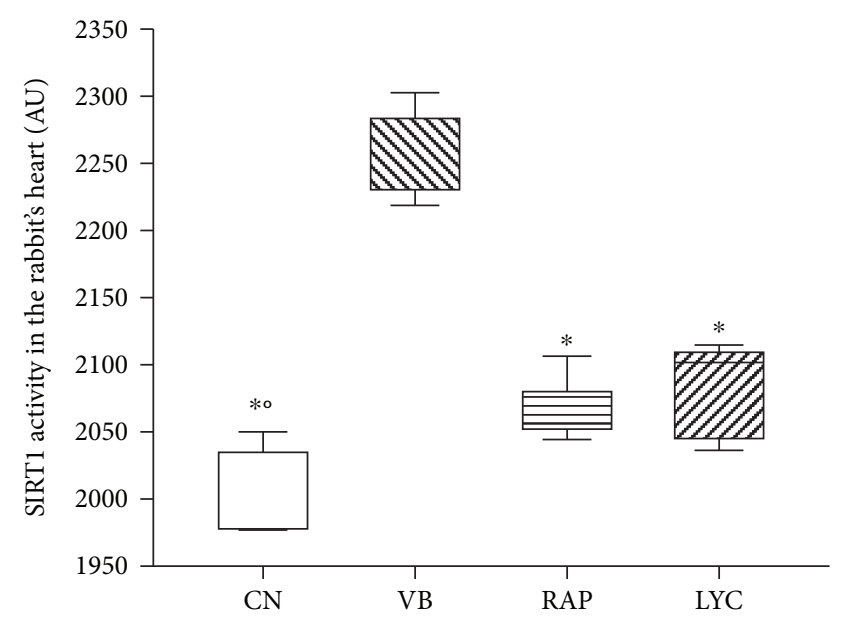

(a)

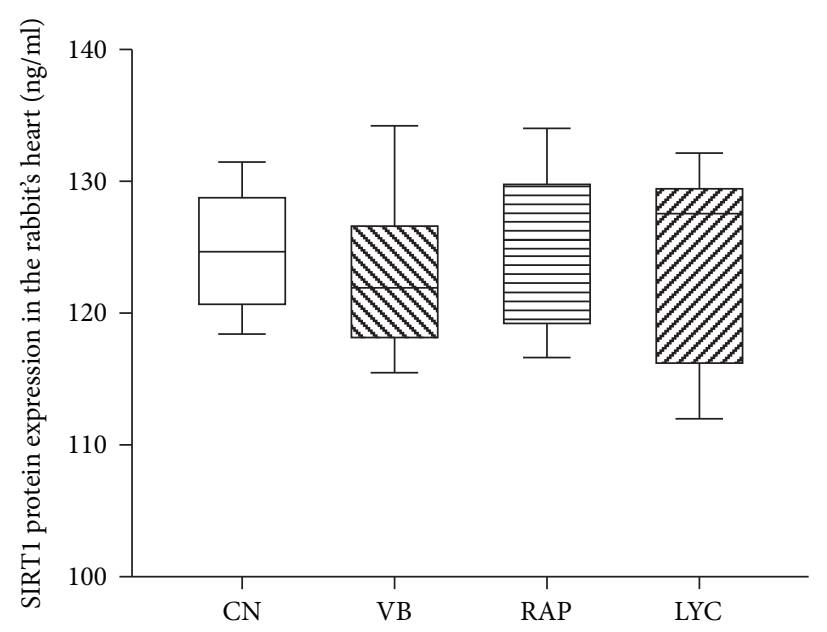

(c)

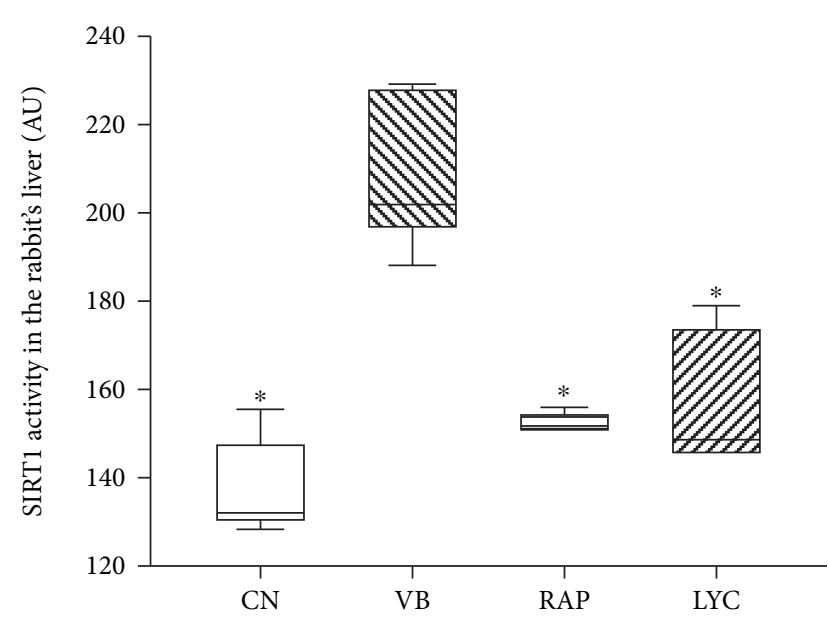

(b)

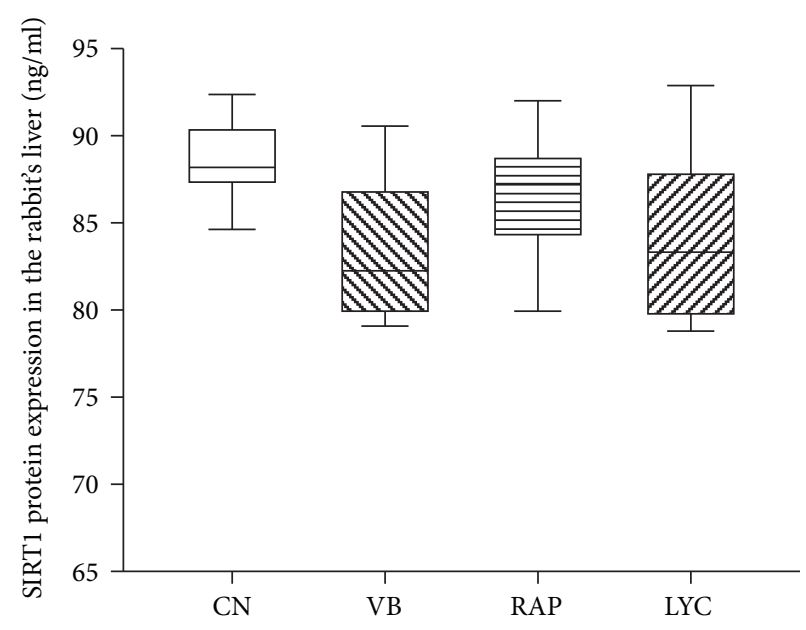

(d)

FIGURE 1: SIRT1 activity in the rabbit's heart (a) and liver (b) and SIRT1 protein expression in the rabbit's heart (c) and liver (d), divided by groups. CN: control; VB: verbascoside; RAP: raphan; LYC: lycopene. ${ }^{*}$ VB versus other groups $(p<0.0001)$; ${ }^{\circ} \mathrm{LYC}$ versus $\mathrm{CN}(p=0.013)$. SIRT1 activity was expressed as arbitrary unit (AU).

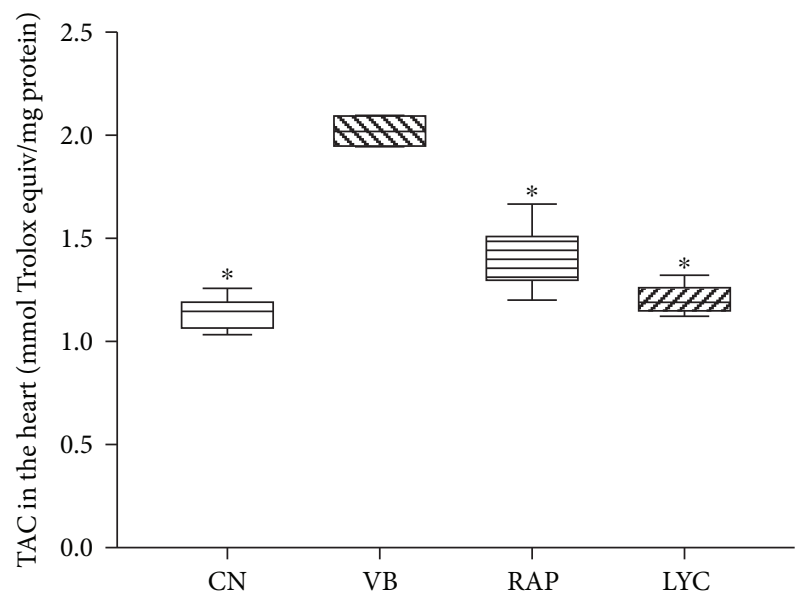

(a)

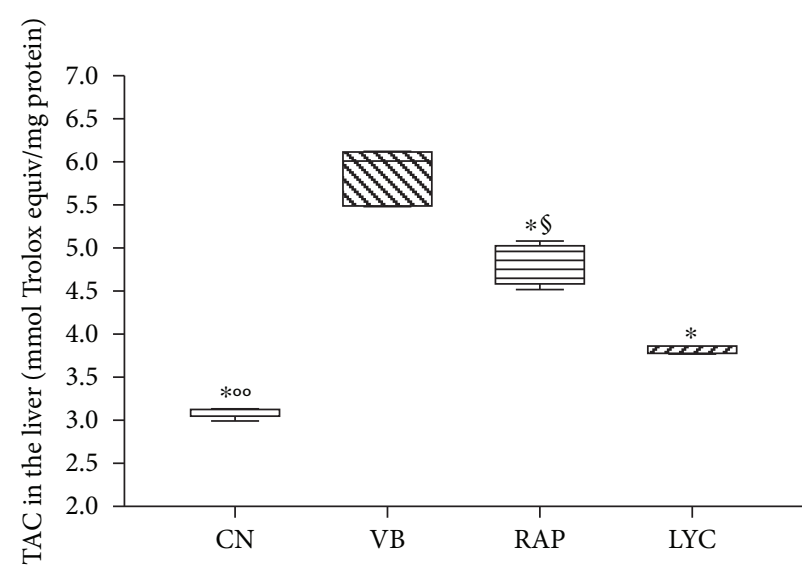

(b)

FIgure 2: Total antioxidant activity (TAC) by the ABTS assay in the rabbit's heart (a) and liver (b), divided by groups. CN: control; VB: verbascoside; RAP: raphan; LYC: lycopene. ${ }^{*} \mathrm{VB}$ versus other groups $(p<0.0001) ;{ }^{\circledR} \mathrm{RAP}$ versus $\mathrm{LYC}(p<0.0001)$; ${ }^{\circ} \mathrm{LYC}$ versus $\mathrm{CN}$ $(p=0.005)$. The ABTS assay was expressed as mmol Trolox equivalent/mg protein. 


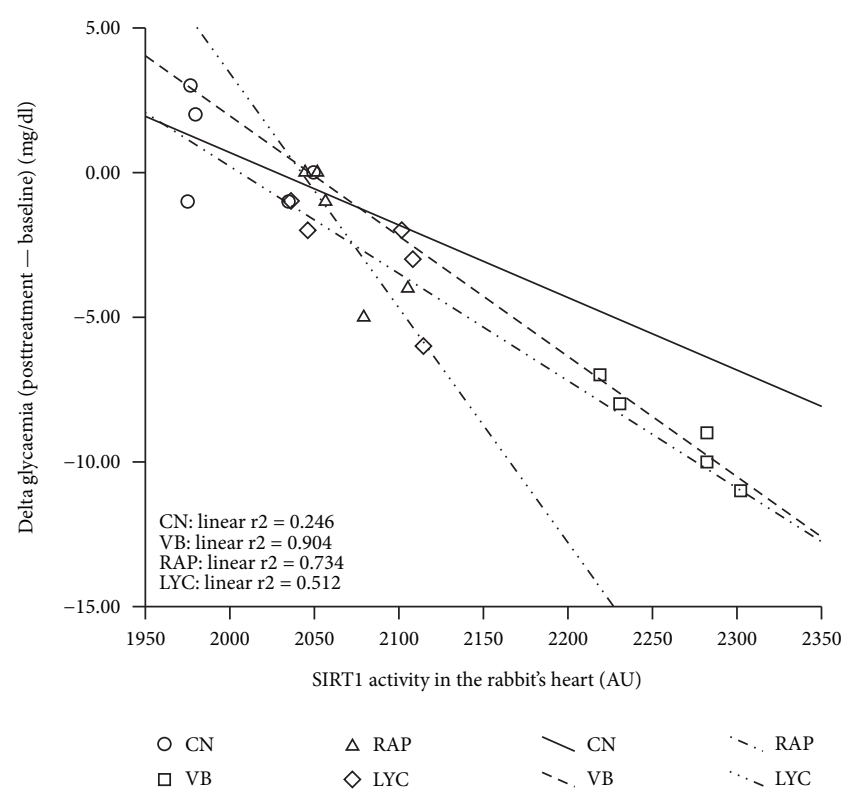

(a)

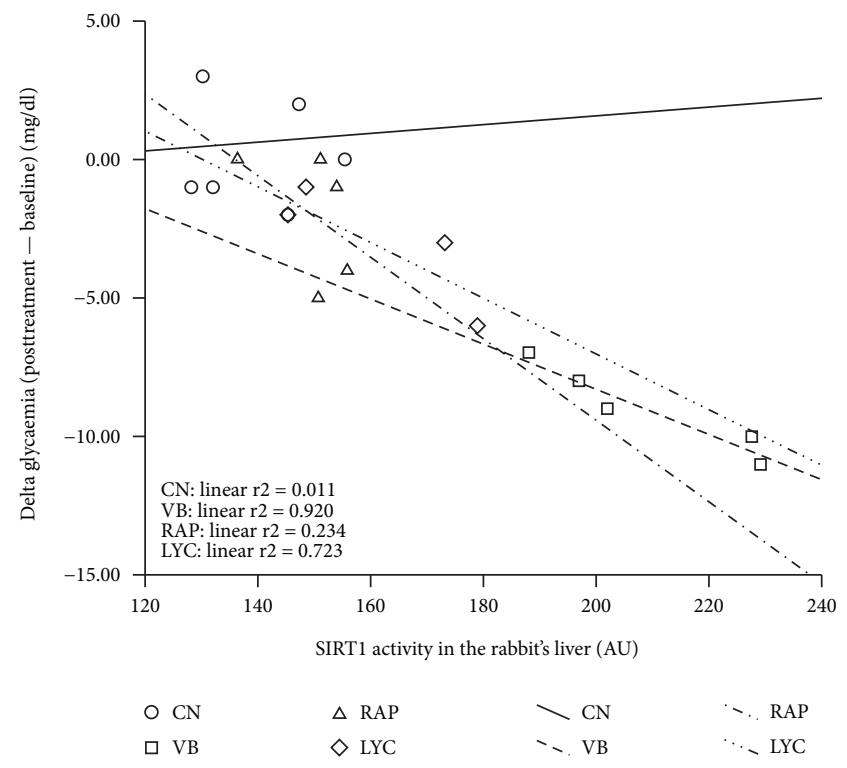

(c)

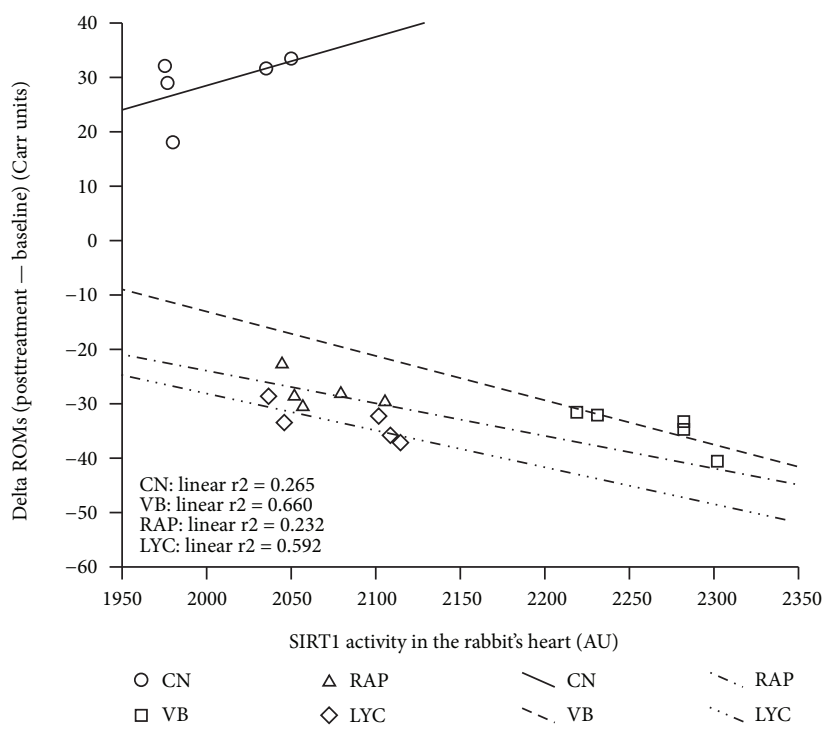

(b)

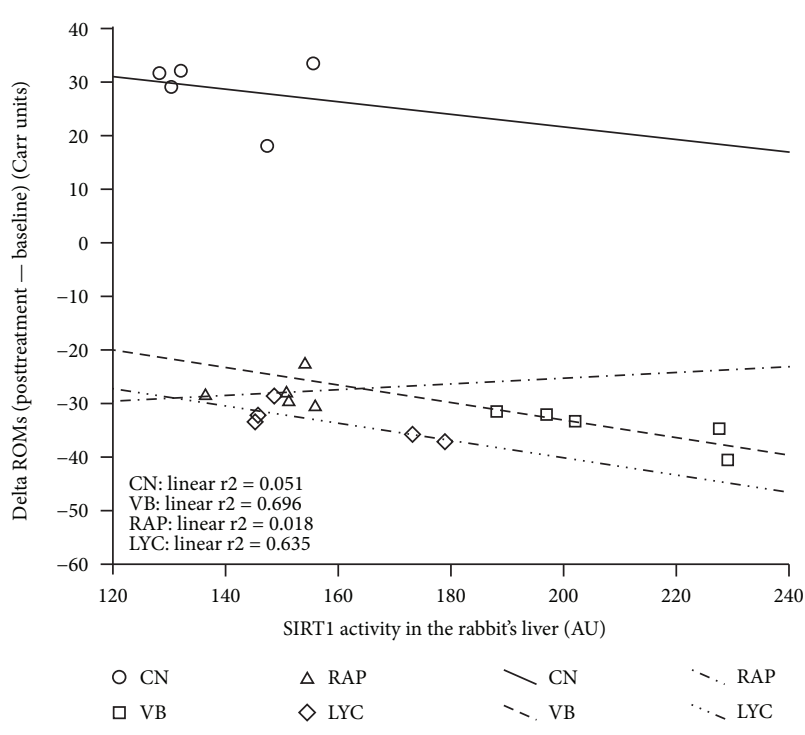

(d)

FIGURE 3: Linear regression by groups between the best predictor delta glycaemia (a) and delta ROMs (b) in the rabbit's heart and between delta glycaemia (c) and delta ROMs (d) in the rabbit's liver. CN: control; VB: verbascoside; RAP: raphan; LYC: lycopene. SIRT1 activity was expressed as arbitrary unit (AU).

due to the antioxidant function of vitamin $\mathrm{E}$ and its role as a regulator of enzymes and gene activity [42]. In our knowledge, this is the first study that demonstrated increased levels of vitamins $\mathrm{A}$ and $\mathrm{E}$ associated with increased SIRT1 activity.

According to Funes et al. [43], the VB biological activity could also be related to its ability to modulate membranedependent cellular processes, such as cell signalling [44] and mitochondrial function $[45,46]$, although the molecular basis of these effects still remains unclear [43].

In addition, Zhang et al. [46] demonstrated that in cells treated with $\mathrm{H}_{2} \mathrm{O}_{2}$, a well-known cellular oxidant, the administration of VB induced a reduction of DNA oxidative damage [46].

Interestingly, $\mathrm{VB}$ and its derivatives are the only wellestablished examples of successful action, due to the concomitant inhibition of expression and DNA binding of the two main proinflammatory transcription factors activator protein- 1 and nuclear factor $\kappa \mathrm{B}$ [47]. Indeed, the activities of the main antioxidant enzymes catalase, glutathione peroxidase, and glutathione reductase showed to be significantly enhanced by VB [48]. Quirantes-Piné et al. [49] showed that after VB administration, the antioxidant enzyme activities significantly augmented while the myeloperoxidase activity 
diminished, suggesting VB protective antioxidant effects on blood cells and its potential anti-inflammatory and antiatherogenic activities in rats. Then, the authors suggested that these VB actions influence redox enzymes at the posttranscriptional level [49]. Furthermore, some data have confirmed that the reduced $\mathrm{NF}-\kappa \mathrm{B}$ activation represents the mechanism responsible for the VB protective effects $[48,50]$.

The NF- $\kappa$ B system regulates apoptosis, proliferation, and energy metabolism and then survival during cellular stress [51-53]. SIRT1 is able to regulate NF- $\kappa \mathrm{B}$ signalling, thereby contributing to the maintenance of cellular homeostasis [54, 55].

In this study, the treatment with VB induced a significant increase in SIRT1 activity in the rabbit's heart, suggesting a possible role of this key redox state regulator in stimulating changes of the oxidant and antioxidant levels. This finding was confirmed by the rise of SIRT1 activity also in the rabbit's liver. We hypothesised that VB is responsible for SIRT1 activation through a hormetic mechanism. The consequent activation of SIRT1 was in turn able to induce the total antioxidant capacity, including enzymes such as catalase and SOD, well-known Sirt1 targets.

Previously, several studies have demonstrated the VB capability to induce an increase in catalase and SOD activity. Recently, Dell'Aquila et al. [56] demonstrated that catalase activity significantly increased in VB-exposed oocytes. The same authors suggested that this increase could be due to the potential formation of $\mathrm{H}_{2} \mathrm{O}_{2}$ during the oxidation of phenolics, concluding that the stimulating effect of VB on CAT activity may also be related to the observed increase in intracellular ROS levels [56]. Also, Sheng et al. [57] revealed that VB significantly decreased apoptotic death in PC12 cells, whereas it increased extracellular hydrogen peroxide levels.

These findings support the hypothesis that a hormetic effect could be responsible for SIRT1 activation, without changes in its expression, and consequent increased antioxidant response.

Finally, the possible explanation of the different behaviours of the other extracts, Raphanus and lycopene, on blood profiles could be related to their dissimilar chemical composition. In fact, the horseradish contains polyphenols derived from flavonoids and lignans, whose titration, however, has not been well defined. Lycopene, on the other hand, is a carotenoid. According to our study that showed also an increase in SIRT1 activity in rabbits treated with lycopene with effects on glycaemic and lipid profiles, Luvizotto et al. [58] showed that lycopene supplementation upregulated mRNA expression of SIRT1 in rats.

\section{Conclusions}

This is the first study that demonstrated a relationship between VB administration and SIrtl activity in the rabbit's heart and liver tissue, suggesting that SIRT1 could mediate the antioxidant effects of this extract. Moreover, these data suggest that all the plant extracts VB, RAP, and LYC in the concentration used are not toxic and able to improve glycaemic and lipid profiles, through induction of antioxidant effects that, in particular for the VB, could be mediated by the SIRT1 activity. Surely, further studies are needed to confirm the possible underlining mechanisms, to investigate the involvement of other sirtuins (such as Sirt3) and to settle the role of hormesis in the antioxidant response induced by these extracts.

\section{Data Availability}

The data used to support the findings of this study are available from the corresponding author upon request.

\section{Conflicts of Interest}

The authors declare to have no conflict of interests.

\section{Authors' Contributions}

Corbi G. and Conti V. contributed equally to this work.

\section{Acknowledgments}

This work was supported by grants from the Department of Health Sciences of the University of Molise (R-DIPA_ 20112013300118).

\section{References}

[1] United Nations, Department of Economic and Social Affairs, Population Division (2015), World Population Ageing, 2015.

[2] T. B. L. Kirkwood, "Understanding the odd science of aging," Cell, vol. 120, no. 4, pp. 437-447, 2005.

[3] M. V. Clément and S. Pervaiz, "Reactive oxygen intermediates regulate cellular response to apoptotic stimuli: an hypothesis," Free Radical Research, vol. 30, no. 4, pp. 247-252, 2009.

[4] W. Chen, H. Su, Y. Xu, T. Bao, and X. Zheng, "Protective effect of wild raspberry (Rubus hirsutus Thunb.) extract against acrylamide-induced oxidative damage is potentiated after simulated gastrointestinal digestion," Food Chemistry, vol. 196, pp. 943-952, 2016.

[5] Y. Li, T. Bao, and W. Chen, "Comparison of the protective effect of black and white mulberry against ethyl carbamateinduced cytotoxicity and oxidative damage," Food Chemistry, vol. 243, pp. 65-73, 2018.

[6] G. Corbi, V. Conti, G. Scapagnini, A. Filippelli, and N. Ferrara, "Role of sirtuins, calorie restriction and physical activity in aging," Frontiers in Bioscience (Elite Edition), vol. 4, pp. 768778, 2012.

[7] G. Corbi, V. Conti, G. Russomanno et al., "Adrenergic signaling and oxidative stress: a role for sirtuins?," Frontiers in Physiology, vol. 4, 2013.

[8] Y. Fu, M. Kinter, J. Hudson et al., "Aging promotes sirtuin 3-dependent cartilage superoxide dismutase 2 acetylation and osteoarthritis," Arthritis \& Rhematology, vol. 68, no. 8, pp. 1887-1898, 2016.

[9] Y. Olmos, F. J. Sánchez-Gómez, B. Wild et al., "SirT1 regulation of antioxidant genes is dependent on the formation of a FoxO3a/PGC-1a complex," Antioxidants \& Redox Signaling, vol. 19, no. 13, pp. 1507-1521, 2013.

[10] K. Huang, C. Chen, J. Hao et al., "Polydatin promotes Nrf2-ARE anti-oxidative pathway through activating Sirt1 to resist AGEs-induced upregulation of fibronetin and 
transforming growth factor- $\beta 1$ in rat glomerular messangial cells," Molecular and Cellular Endocrinology, vol. 399, pp. 178-189, 2015.

[11] G. Corbi, V. Conti, S. Davinelli, G. Scapagnini, A. Filippelli, and N. Ferrara, "Dietary phytochemicals in neuroimmunoaging: a new therapeutic possibility for humans?," Frontiers in Pharmacology, vol. 7, 2016.

[12] S. Davinelli, M. Maes, G. Corbi, A. Zarrelli, D. C. Willcox, and G. Scapagnini, "Dietary phytochemicals and neuro-inflammaging: from mechanistic insights to translational challenges," Immunity \& Ageing, vol. 13, no. 1, article 16, 2016.

[13] P. Mellini, S. Valente, and A. Mai, "Sirtuin modulators: an updated patent review (2012 - 2014)," Expert Opinion on Therapeutic Patents, vol. 25, no. 1, pp. 5-15, 2015.

[14] S. Davinelli, G. Scapagnini, F. Marzatico, V. Nobile, N. Ferrara, and G. Corbi, "Influence of equol and resveratrol supplementation on health-related quality of life in menopausal women: a randomized, placebo-controlled study," Maturitas, vol. 96, pp. 77-83, 2017.

[15] K. Prasad, V. Sharma, K. Lackore, S. M. Jenkins, A. Prasad, and A. Sood, "Use of complementary therapies in cardiovascular disease," The American Journal of Cardiology, vol. 111, no. 3, pp. 339-345, 2013.

[16] W. Chen, J. Zhuang, Y. Li, Y. Shen, and X. Zheng, "Myricitrin protects against peroxynitrite-mediated DNA damage and cytotoxicity in astrocytes," Food Chemistry, vol. 141, no. 2, pp. 927-933, 2013.

[17] D. Casamassima, M. Palazzo, F. Vizzarri, C. Costagliola, C. Corino, and A. Di Costanzo, "Dietary effects of plant extracts, based on verbascoside, lycopene and horseradish on several blood variables and plasma oxidative status in growing rabbits," Livestock Science, vol. 206, pp. 148-153, 2017.

[18] G. Campo, R. Pavasini, S. Biscaglia et al., "Platelet aggregation values in patients with cardiovascular risk factors are reduced by verbascoside treatment. A randomized study," Pharmacological Research, vol. 97, pp. 1-6, 2015.

[19] G. Campo, J. Marchesini, L. Bristot et al., "The in vitro effects of verbascoside on human platelet aggregation," Journal of Thrombosis and Thrombolysis, vol. 34, no. 3, pp. 318-325, 2012.

[20] M. R. Cesarone, G. Belcaro, M. Carratelli et al., "A simple test to monitor oxidative stress," International Angiology, vol. 18, no. 2, pp. 127-130, 1999.

[21] H. Esterbauer and H. Zollern, "Methods for determination of aldehydic lipid peroxidation products," Free Radical Biology \& Medicine, vol. 7, no. 2, pp. 197-203, 1989.

[22] B. Zhao, S. Y. Tham, J. Lu, M. H. Lai, L. K. Lee, and S. M. Moochhala, "Simultaneous determination of vitamins C, E and beta-carotene in human plasma by high-performance liquid chromatography with photodiode-array detection," Journal of Pharmacy \& Pharmaceutical Sciences, vol. 7, no. 2, pp. 200-204, 2004.

[23] N. Ferrara, B. Rinaldi, G. Corbi et al., "Exercise training promotes SIRT1 activity in aged rats," Rejuvenation Research, vol. 11, no. 1, pp. 139-150, 2008.

[24] R. Re, N. Pellegrini, A. Proteggente, A. Pannala, M. Yang, and C. Rice-Evans, "Antioxidant activity applying an improved ABTS radical cation decolorization assay," Free Radical Biology \& Medicine, vol. 26, no. 9-10, pp. 1231-1237, 1999.

[25] T. Kushiro, E. Nambara, and P. McCourt, "Hormone evolution: the key to signalling," Nature, vol. 422, no. 6928, p. 122, 2003.
[26] I. Dalle-Donne, R. Rossi, G. Colombo, D. Giustarini, and A. Milzani, "Protein S-glutathionylation: a regulatory device from bacteria to humans," Trends in Biochemical Sciences, vol. 34, no. 2, pp. 85-96, 2009.

[27] J. G. Scandalios, "Oxidative stress: molecular perception and transduction of signals triggering antioxidant gene defenses," Brazilian Journal of Medical and Biological Research, vol. 38, no. 7, pp. 995-1014, 2005.

[28] C. Jiménez and R. Riguera, "Phenylethanoid glycosides in plants: structure and biological activity," Natural Product Reports, vol. 11, no. 6, pp. 591-606, 1994.

[29] M. Pennacchio, Y. M. Syah, E. L. Ghisalberti, and E. Alexander, "Cardioactive compounds from Eremophila species," Journal of Ethnopharmacology, vol. 53, no. 1, pp. 21-27, 1996.

[30] R. Rossi, G. Pastorelli, S. Cannata, S. Tavaniello, G. Maiorano, and C. Corino, "Effect of long term dietary supplementation with plant extract on carcass characteristics meat quality and oxidative stability in pork," Meat Science, vol. 95, no. 3, pp. 542-548, 2013.

[31] J. Iglesias, M. Pazos, J. L. Torres, and I. Medina, “Antioxidant mechanism of grape procyanidins in muscle tissues: redox interactions with endogenous ascorbic acid and a-tocopherol," Food Chemistry, vol. 134, no. 4, pp. 1767-1774, 2012.

[32] M. Palazzo, F. Vizzarri, M. Cinone, C. Corino, and D. Casamassima, "Assessment of a natural dietary extract, titrated in phenylpropanoid glycosides, on blood parameters and plasma oxidative status in intensively reared Italian hares (Lepus corsicanus)," Animal, vol. 5, no. 06, pp. 844-850, 2011.

[33] H. M. G. Princen, W. van Duyvenvoorde, R. Buytenhek et al., "No effect of consumption of green and black tea on plasma lipid and antioxidant levels and on LDL oxidation in smokers," Arteriosclerosis, Thrombosis, and Vascular Biology, vol. 18, no. 5, pp. 833-841, 1998.

[34] Q. Y. Zhu, Y. Huang, D. Tsang, and Z. Y. Chen, "Regeneration of alpha-tocopherol in human low-density lipoprotein by green tea catechin," Journal of Agricultural and Food Chemistry, vol. 47, no. 5, pp. 2020-2025, 1999.

[35] K. Liao and M. Yin, "Individual and combined antioxidant effects of seven phenolic agents in human erythrocyte membrane ghosts and phosphatidylcholine liposome systems: importance of the partition coefficient," Journal of Agricultural and Food Chemistry, vol. 48, no. 6, pp. 2266-2270, 2000.

[36] J. K. Miller, E. Brzezinska-Slebodzinska, and F. C. Madsen, "Oxidative stress, antioxidants, and animal function," Journal of Dairy Science, vol. 76, no. 9, pp. 2812-2823, 1993.

[37] L. J. Machlin and E. Vitamin, Handbook of Vitamins, L. J. Machlin, Ed., Dekker, New York, 1991.

[38] A. Bast and G. R. M. M. Haenen, "The toxicity of antioxidants and their metabolites," Environmental Toxicology and Pharmacology, vol. 11, no. 3-4, pp. 251-258, 2002.

[39] A. G. D'Alessandro, D. Casamassima, F. Jirillo, and G. Martemucci, "Effects of verbascoside administration on the blood parameters and oxidative status in jennies and their suckling foals: potential improvement of milk for human use," Endocrine, Metabolic \& Immune Disorders Drug Targets, vol. 14, no. 2, pp. 102-112, 2014.

[40] A. Wu, Z. Ying, and F. Gomez-Pinilla, "Oxidative stress modulates Sir2alpha in rat hippocampus and cerebral cortex," The European Journal of Neuroscience, vol. 23, no. 10, pp. 2573-2580, 2006. 
[41] M. Carola Zillikens, J. B. J. van Meurs, F. Rivadeneira et al., "Interactions between dietary vitamin E intake and SIRT1 genetic variation influence body mass index," The American Journal of Clinical Nutrition, vol. 91, no. 5, pp. 1387-1393, 2010.

[42] R. Brigelius-Flohe, "Vitamin E: the shrew waiting to be tamed," Free Radical Biology \& Medicine, vol. 46, no. 5, pp. 543-554, 2009.

[43] L. Funes, O. Laporta, M. Cerdán-Calero, and V. Micol, "Effects of verbascoside, a phenylpropanoid glycoside from lemon verbena, on phospholipid model membranes," Chemistry and Physics of Lipids, vol. 163, no. 2, pp. 190-199, 2010.

[44] K. J. Lee, E. R. Woo, C. Y. Choi et al., "Protective effect of acteoside on carbon tetrachloride-induced hepatotoxicity," Life Sciences, vol. 74, no. 8, pp. 1051-1064, 2004.

[45] K. A. Koo, S. H. Kim, T. H. Oh, and Y. C. Kim, "Acteoside and its aglycones protect primary cultures of rat cortical cells from glutamate-induced excitotoxicity," Life Sciences, vol. 79, no. 7, pp. 709-716, 2006.

[46] Q. Zhang, J. Pan, C. Zhao, Y. Wang, Z. Jia, and R. Zheng, "Non-enzymatic fast repair of DNA oxidative damage might also exist in cells," Cell Biology International, vol. 32, no. 6, pp. 654-662, 2008.

[47] S. Pastore, D. Lulli, P. Fidanza et al., "Plant polyphenols regulate chemokine expression and tissue repair in human keratinocytes through interaction with cytoplasmic and nuclear components of epidermal growth factor receptor system," Antioxidants \& Redox Signaling, vol. 16, no. 4, pp. 314-328, 2012.

[48] K. Alipieva, L. Korkina, I. E. Orhan, and M. I. Georgiev, "Verbascoside-a review of its occurrence, (bio)synthesis and pharmacological significance," Biotechnology Advances, vol. 32, no. 6, pp. 1065-1076, 2014.

[49] R. Quirantes-Piné, M. Herranz-López, L. Funes et al., "Phenylpropanoids and their metabolites are the major compounds responsible for blood-cell protection against oxidative stress after administration of Lippia citriodora in rats," Phytomedicine, vol. 20, no. 12, pp. 1112-1118, 2013.

[50] E. Mazzon, E. Esposito, R. Di Paola et al., "Effects of verbascoside biotechnologically produced by Syringa vulgaris plant cell cultures in a rodent model of colitis," Naunyn-Schmiedeberg's Archives of Pharmacology, vol. 380, no. 1, pp. 79-94, 2009.

[51] M. Karin and A. Lin, "NF-kappaB at the crossroads of life and death," Nature Immunology, vol. 3, no. 3, pp. 221-227, 2002.

[52] N. D. Perkins, "Integrating cell-signalling pathways with NF-kappaB and IKK function," Nature Reviews. Molecular Cell Biology, vol. 8, no. 1, pp. 49-62, 2007.

[53] R. F. Johnson and N. D. Perkins, "Nuclear factor- $\kappa$ B, p53, and mitochondria: regulation of cellular metabolism and the Warburg effect," Trends in Biochemical Sciences, vol. 37, no. 8, pp. 317-324, 2012.

[54] F. Yeung, J. E. Hoberg, C. S. Ramsey et al., "Modulation of NF-kappaB-dependent transcription and cell survival by the SIRT1 deacetylase," The EMBO Journal, vol. 23, no. 12, pp. 2369-2380, 2004.

[55] M. J. Morgan and Z. G. Liu, "Crosstalk of reactive oxygen species and NF- $\kappa \mathrm{B}$ signaling," Cell Research, vol. 21, no. 1, pp. 103-115, 2011.

[56] M. E. Dell'Aquila, L. Bogliolo, R. Russo et al., "Prooxidant effects of verbascoside, a bioactive compound from olive oil mill wastewater, on in vitro developmental potential of ovine prepubertal oocytes and bioenergetic/oxidative stress parameters of fresh and vitrified oocytes," BioMed Research International, vol. 2014, Article ID 878062, 14 pages, 2014.

[57] G. Q. Sheng, J. R. Zhang, X. P. Pu, J. Ma, and C. L. Li, “Protective effect of verbascoside on 1-methyl-4-phenylpyridinium ion-induced neurotoxicity in PC12 cells," European Journal of Pharmacology, vol. 451, no. 2, pp. 119-124, 2002.

[58] R. A. Luvizotto, A. F. Nascimento, N. C. Miranda, X. D. Wang, and A. L. Ferreira, "Lycopene-rich tomato oleoresin modulates plasma adiponectin concentration and mRNA levels of adiponectin, SIRT1, and FoxO1 in adipose tissue of obese rats," Human \& Experimental Toxicology, vol. 34, no. 6, pp. 612619, 2015. 


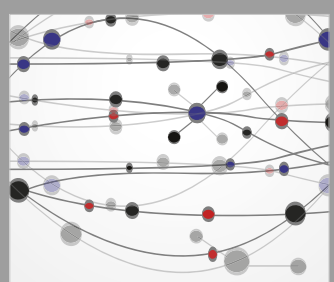

The Scientific World Journal
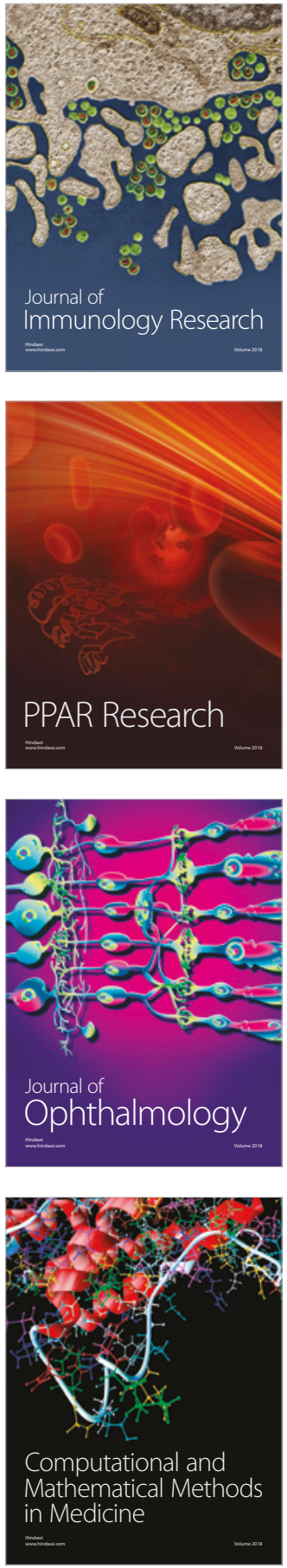

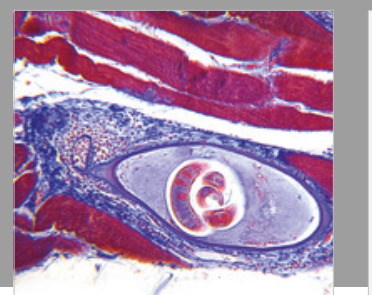

Gastroenterology Research and Practice

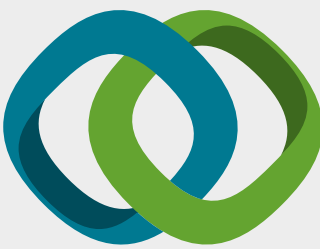

\section{Hindawi}

Submit your manuscripts at

www.hindawi.com
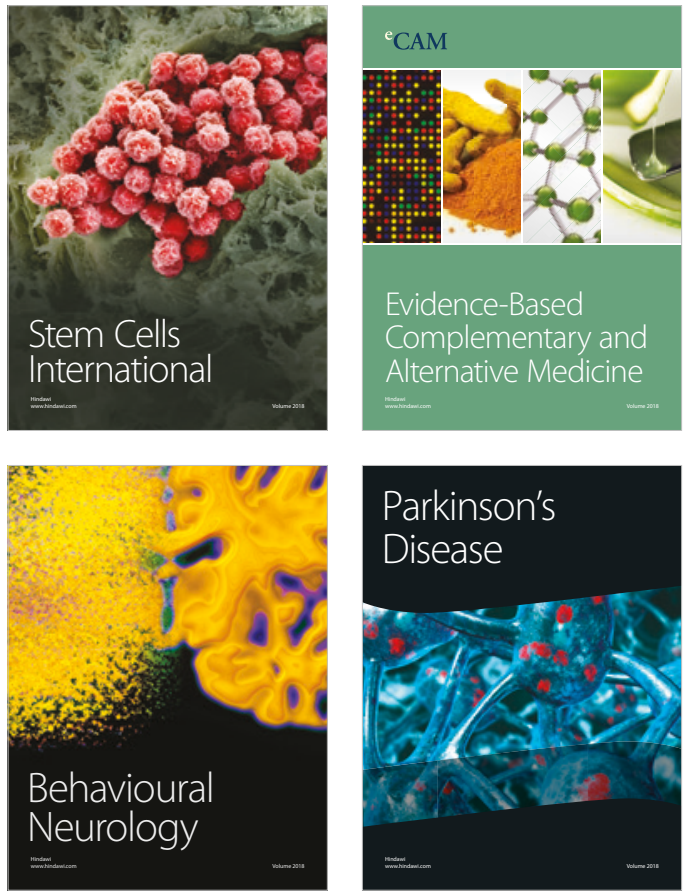

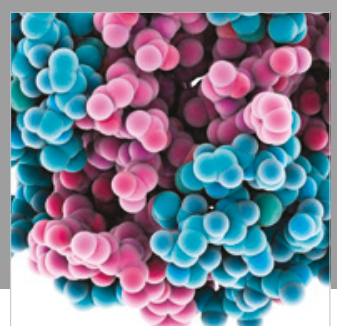

ournal of

Diabetes Research

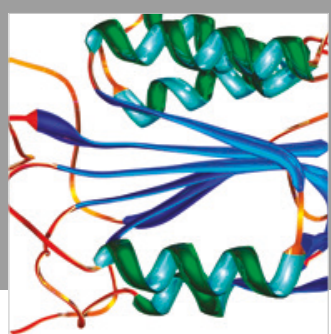

Disease Markers
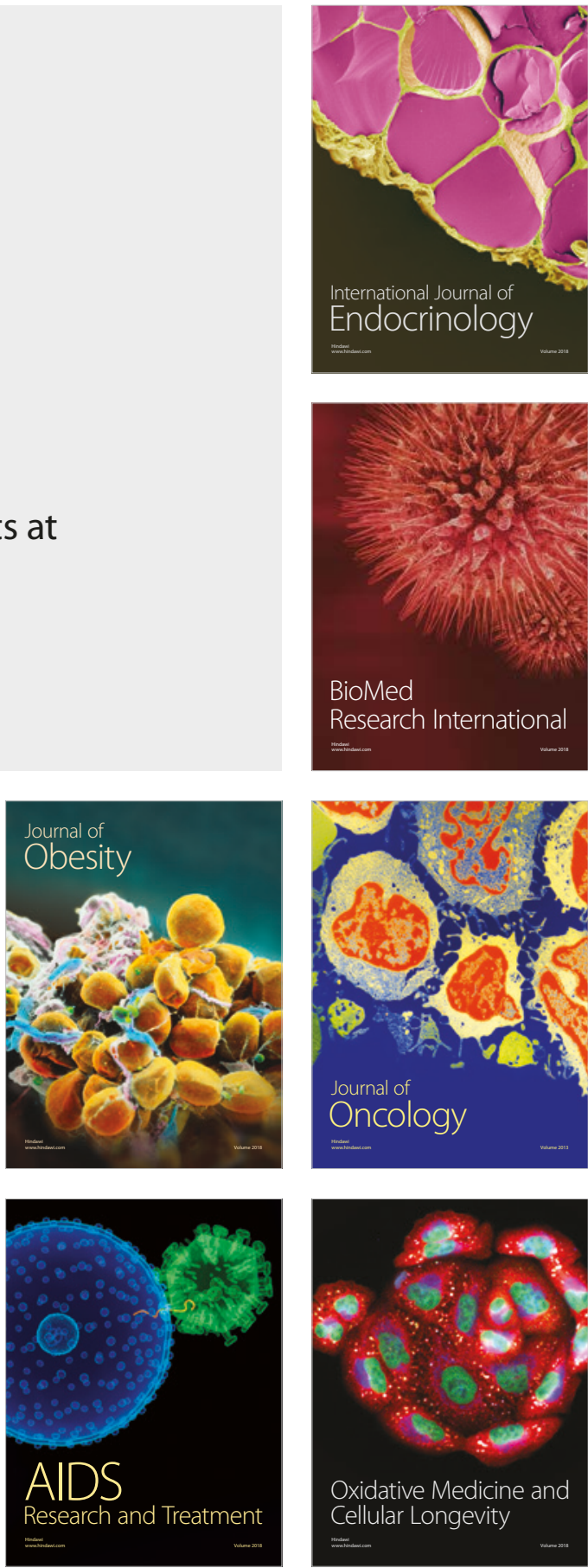